\title{
Parental perception of psychophysical health, nutritional status and oral health in relation to sociodemographic characteristics in children in Bariloche, Argentina: an epidemiological study
}

\author{
Gilda Garibotti, Ph.D. in Statistics ${ }^{a}$, Cecilia Vasconi, B.S. in Social Services ${ }^{b}$, \\ Alejandra Ferrari, M.D. ${ }^{d}$, Gabriela Giannini, M.D. ${ }^{d}$, Haydeé Comar, M.D. ${ }^{c, d}$, \\ and Diego Schnaiderman, M.D. ${ }^{d}$
}

\begin{abstract}
Introduction. There is evidence of an association between social determinants and child health. Objective. To identify sociodemographic characteristics related to child health inequalities and to analize the cumulative effect on health of risk factors based on these characteristics.

Population and Methods. We evaluated 4-13 year-old children in Bariloche between June 2008 and May 2009. The following sociodemographic characteristics were taken into account: socioeconomic level, maternal education, adolescent pregnancy, medical coverage, unsafeness, and family habits. We assessed parental perception of physical, and social and emotional health, nutritional status and oral health in relation to these characteristics and the accumulation of risk factors. We used survey, anthropometry and oral examination.

Results. One hundred and eighty students participated. The level of maternal education was associated with the child's physical, social and emotional, and oral health. The percentage of children with missing teeth or cavities reached $77 \%$ among those whose mothers had, at most, completed primary school, compared to $13 \%$ among those whose mothers had completed tertiary school or university.

The possibility of perceiving a non-optimal physical, and social and emotional health increased 1.8 and 1.4 times with each risk factor, respectively, and the possibility of having missing teeth or cavities was twice as much with each additional risk factor.

Overweight and obesity was observed in $27.3 \%$ and $8.7 \%$ of students, respectively, and no relationship was found with sociodemographic characteristics.

Conclusions. A low family socioeconomic level and a low maternal education level were associated with a higher prevalence of unfavorable health outcomes. Multiple risk factors have an cumulative effect on parental perception of physical, social and emotional, and oral health.

Key words: health inequalities, epidemiology, child health, Argentina.
\end{abstract}

http:/ /dx.doi.org/10.5546/aap.2015.eng.411

\section{INTRODUCTION}

Child health has remarkably improved in the $20^{\text {th }}$ century, among other things, because of the reduction in the incidence of infectious diseases and overall mortality. ${ }^{1}$ However, such improvements were not the same in all countries nor in all regions within each country. ${ }^{2}$

Several investigations found disparities in different health aspects among the Argentine pediatric population. The relationship between a higher socioeconomic status and a better performance in developmental milestones has been well-established, even in studies conducted in Argentina. ${ }^{3-5}$ Like many other developing countries, Argentina is experiencing a significant increase in the prevalence of childhood overweight and obesity. Results in terms of the relationship between the lowest socioeconomic status and overweight and obesity have been inconsistent.

Although a few decades ago obesity was considered a problem of high-income social sectors, at present, it affects children from different social levels to a similar extent. ${ }^{6-10}$ In different regions of Argentina, it was determined that children whose families had a lower income had a high level of oral diseases. ${ }^{11,12}$ Child mortality rates vary depending on the population's socioeconomic status; being higher among groups with a high prevalence of unmet basic needs. ${ }^{13,14}$

Epidemiological studies on child health indicators associated with living conditions allow to establish 
the extent and distribution of inequalities. Such knowledge is necessary to design health policies targeted at reducing such inequalities. At present, health is not only defined as the absence of disease, but as the condition of psychophysical and social well-being that allows individuals to develop and attain their full potential, meet their needs and develop skills to successfully interact with their environment. ${ }^{15,16}$ From this perspective, the assessment of child health requires considering a broad range of indicators.

The objective of this study is to identify sociodemographic characteristics associated with inequalities in parental perception of their children's physical and social and emotional health, nutritional status and oral health, and assess the cumulative effect of risk factors related to these health characteristics of the school-age population in the city of Bariloche.

\section{POPULATION AND METHODS}

This study was conducted based on an anonymous survey administered to the father or mother of 4-13 year-old children in Bariloche, together with children's anthropometric status and oral health examination (Annex 1). Surveys were administered at the 2 de Abril Health Center (one of the neighbourhoods with the lowest socioeconomic status in town), at outpatient offices of the health insurance provided by the Restaurant Workers Union and Trade Workers Union, and at a private pediatric clinic. It is assumed that families seen at these facilities are representative of the different social sectors in Bariloche. Children with chronic diseases that may affect their psychophysical development were excluded.

Since there were no previous local data on the distribution of health outcomes of interest, the sample size was estimated to be 200 children, accounting for approximately $1 \%$ of the 5-14 yearold population in Bariloche (2001 Census, INDEC). At the union health insurance outpatient offices and the private clinic, participants were randomly selected among patients with an appointment to see the pediatricians who were also authors of this article: one patient per day per pediatrician. At the Health Center, surveys were administered by one of the pediatricians on different days and times. Interviews were conducted between June 2008 and May 2009. Mothers and fathers were invited to participate, received information on the project, and were asked for their oral consent. The research protocol was approved by the Teaching and Research Committee of the Bariloche Regional Hospital.

The survey was developed based on the United States' 2003 National Survey of Children's Health. ${ }^{17,18}$ It was used as a reference given the varied health aspects covered and because it asks about parental perception on their children's health.

\section{Child health outcomes}

Health outcomes were parental perception of their children's physical and social and emotional health, nutritional status, and oral health.

- Physical health. As per parental perception, children's health status was classified by the surveyed parent as excellent, very good, good, fair or poor. For analysis purposes, health status was classified into optimal (very good/excellent) or non-optimal (poor/fair/ good).

- Social and emotional health. Fathers/ mothers were asked whether they were concerned about their child's behavior, academic performance, ability to understand instructions, relationship with other children and adults (teachers, parents, etc.), depression or anxiety, ability to solve conflictive situations, and manner of speech. The total number of topics that concerned the surveyed parents was estimated. Answers were divided into quartiles; children in the upper quartile were considered to have a non-optimal social and emotional health. Parental concern has a high predictive value on social and emotional health. ${ }^{19,20}$

- Nutritional status. Children's weight was recorded using a CAM standing scale; an altimeter was used to measure heights over $110 \mathrm{~cm}$ and an infantometer for heights below $110 \mathrm{~cm}$. Based on their body mass index (BMI), children were categorized as eutrophic (normal weight), overweight, obese or thin according to the international reference from the Obesity Task Force. ${ }^{21,22}$ For analysis purposes, children were grouped as overweight or obese (yes/no).

- Oral health. A physician verified the presence of cavities or missing teeth resulting from an intentional tooth extraction by a dentist due to oral disease (yes/no).

\section{Sociodemographic characteristics}

Sociodemographic characteristics included family affluence scale (FAS), maximum education 
level attained by the mother, adolescent pregnancy, type of medical coverage, unsafe neighborhood or school, single-parent household, reading habit, and time spent in front of the TV and/or computer.

- Family affluence scale. A model similar to the one proposed by Currie, et al. ${ }^{23}$ was used; it consists of considering a set of items reflecting the level of family expenditure. The number of affirmative answers to the following items was recorded: the family has a car, a computer, does not receive social benefits, the child went out on vacations at least once in the past year, and the child shares the bedroom with less than three persons. High values were associated with a higher family affluence scale. Categories: low ( 0 or 1$)$, middle $(2,3$ or 4$)$, or high (5).

- Maximum education level attained by the mother. The following categories were considered: no education/primary, secondary, tertiary/university.

- Adolescent pregnancy. It refers to pregnancy in a woman younger than 19 years old.

- Type of medical coverage. The following categories were considered: no coverage, group health plan funded by a labor union, HMO plan.

- Unsafe neighborhood or school. Parental perception regarding how safe the child is in the neighborhood or school. As per the survey, this was classified into never, sometimes, always or usually. For analysis purposes, this was divided into never/sometimes versus always/usually.

- Single-parent household. A household made up of only one of the child's parents.

- Reading habit. A child who read or had a family member read to him/her a short story or part of a novel at least once during the past week was considered as having a reading habit.

- Time spent in front of the TV. Children were classified as exposed to TV or computer for three or more hours a day o less than three hours a day.

The following risk factors were considered: low FAS, no education/primary school as the maximum education level attained by the mother, adolescent pregnancy, lack of medical coverage, dangerous neighborhood or school, single-parent household, not having a reading habit, and spending three or more hours per day in front of the TV or computer.

\section{Statistical analysis}

Mean age and standard deviation of studied children and the percent distribution of health outcomes and sociodemographic characteristics were established.

For each health outcome, the relationship of sociodemographic characteristics was studied separately, and the possibility of such outcome having an unfavorable result was considered using Pearson's chi-square test.

The association between the number of risk factors and health outcomes was assessed using a logistic regression model.

Data were processed and analyzed using the R 3.1.1 statistical package. ${ }^{24}$

\section{RESULTS}

One hundred and eighty children participated: 53 from 2 de Abril Health Center, 61 from the outpatient offices of the health insurance provided by the Restaurant Workers Union and Trade Workers Union, and 66 from a private pediatric clinic. No family refused to be interviewed. Children's mean age was 8.1 years old (standard deviation: 2.8 years old), and 51\% were of male sex. Mothers were interviewed in $80 \%$ of cases. Descriptive statistics of health outcomes, sociodemographic characteristics and number of risk factors are shown in Table 1. Thirty-six percent of parents perceive their children have a non-optimal physical health, while $23 \%$ perceive that they have a non-optimal social and emotional health. Among children, 36\% are overweight or obese, and almost $50 \%$ have cavities or missing teeth. Most children (83\%) had one risk factor; approximately $50 \%$ had two or more, and $28 \%$ had four or more risk factors.

Table 2 shows there is a gradient in the likelihood of children having a non-optimal physical health in relation to the FAS, which is $9 \%$ with a high FAS and $79 \%$ with a low FAS. A similar pattern is observed in relation to social and emotional health and oral health, but not in terms of overweight or obesity $(\mathrm{p}=0.134)$. Tertiary / university maternal education is associated with fewer possibilities of having a non-optimal physical health, both when compared to children whose mothers completed secondary school and to those whose mothers received no education or only completed primary school. Pediatric oral health inversely worsens with maternal education, and goes from $77 \%$ in children whose mothers completed at most primary school to $13 \%$ in those whose mothers completed tertiary school 
or university. No significant differences were found in the prevalence of overweight or obesity in relation to the studied factors.

Figure 1 shows the effect of risk factor accumulation on child health. The percentage of children with non-optimal physical health among those without risk factors was approximately $10 \%$ and gradually increased to $90 \%$ among those with six or more risk attributes. The logistic regression model was adjusted considering nonoptimal physical health as a dependent variable $($ yes $=1 ;$ no $=0)$ and the number of risk factors as an independent variable. The odds ratio was estimated to be 1.8 ( $\mathrm{p}<0.001)$. The possibility of parental perception of non-optimal physical health increased 1.8 times with each additional risk factor. In the group of children without risk attributes, less than $5 \%$ of children had a non- optimal social and emotional health, compared to $50 \%$ among those with five or six risk factors. Parental perception of non-optimal social and emotional health increased 1.4 times $(\mathrm{p}<0.001)$ with each additional risk factor.

The odds ratio of the logistic regression model with the overweight or obesity variable was not significant.

The number of risk factors also accounts for oral health. Each additional risk factor doubled $(p<0.001)$ the possibility of having cavities or missing teeth.

\section{DISCUSSION}

Health inequalities are a global problem. ${ }^{2}$ The World Health Organization defines health inequality as "unnecessary, avoidable and unjust health disparities." 25 Thus, in operational terms,

TABLE 1. Health outcomes, sociodemographic characteristics and number of risk factors among students in Bariloche ( $n=180)$

\begin{tabular}{|c|c|c|}
\hline Characteristic & Categories & n (\%) \\
\hline \multicolumn{3}{|l|}{ Health outcomes } \\
\hline \multirow[t]{5}{*}{ Physical health* } & Excellent & $46(25.3)$ \\
\hline & Very good & $69(38.2)$ \\
\hline & Good & $61(33.7)$ \\
\hline & Fair & $4(2.2)$ \\
\hline & Poor & $1(0.6)$ \\
\hline Social and emotional health* & Non-optimal & $41(22.8)$ \\
\hline \multirow[t]{4}{*}{ Nutritional status } & Normal & $109(60.5)$ \\
\hline & Thin & $6(3.5)$ \\
\hline & Overweight & $49(27.3)$ \\
\hline & Obesity & $16(8.7)$ \\
\hline Cavities or missing teeth & Yes & $89(49.4)$ \\
\hline \multicolumn{3}{|l|}{ Sociodemographic characteristics } \\
\hline \multirow[t]{3}{*}{ Family affluence scale } & Low & $28(15.7)$ \\
\hline & Medium & $91(50.6)$ \\
\hline & High & $61(33.7)$ \\
\hline \multirow{3}{*}{ Maximum education level attained by the mother } & No education or primary school & $79(44.1)$ \\
\hline & Secondary school & $53(29.6)$ \\
\hline & Tertiary school or university & $47(26.3)$ \\
\hline Adolescent pregnancy & Yes & $47(26.2)$ \\
\hline \multirow[t]{3}{*}{ Type of medical coverage } & None & $46(25.8)$ \\
\hline & Group health plan funded by a labor union & $91(50.6)$ \\
\hline & HMO plan & $42(23.6)$ \\
\hline Unsafe neighborhood or school & Yes & $76(42.2)$ \\
\hline Single-parent household & Yes & $55(30.7)$ \\
\hline Reading habit & No & $88(48.9)$ \\
\hline Time spent in front of the TV & 3 or more hours & $28(15.7)$ \\
\hline \multirow[t]{8}{*}{ Number of risk factors } & 0 & $30(16.7)$ \\
\hline & 1 & $52(28.9)$ \\
\hline & 2 & $27(15.0)$ \\
\hline & 3 & $20(11.1)$ \\
\hline & 4 & $20(11.1)$ \\
\hline & 5 & $12(6.7)$ \\
\hline & 6 & $12(6.7)$ \\
\hline & 7 or 8 & $7(3.9)$ \\
\hline
\end{tabular}

\footnotetext{
* Parental perception of nutritional status.
} 
health equality consists of minimizing avoidable disparities together with their determinants among people with different levels of privilege or advantages. ${ }^{26}$ The first step to address this problem is to identify disparities and their determining factors. This study identified important health gaps in the child population in Bariloche in relation to studied health aspects, except for the nutritional status.

Maternal education level showed a significant association with physical, social and emotional, and oral health, and increased the prevalence of unfavorable health outcomes through a reverse relationship with the level of education. The level of maternal education is connected to childrearing: feeding, ability to create an environment where learning and knowledge are encouraged, and commitment with preventive measures in relation to dental care, among other things. In addition, it is an indicator of health literacy, which is relevant because low literacy in health interferes with the communication between health care providers and patients, makes treatment understanding difficult, and has an impact on treatment dropout. ${ }^{27}$ In this sense, it is important to have policies that promote continuous education among youth and adults, and health programs such as the ProSanE, a school health program that proposes medical and oral examinations for all students from first to sixth grade..$^{28}$

Cavities are one of the most common chronic diseases during childhood. Several studies have found a relationship between maternal education and oral health. .11,12,29 $^{2}$

Among children whose mothers had completed at most primary school, $77 \%$ had cavities or missing teeth, compared to $40 \%$ among those whose mothers had finished secondary school, and 13\% among those whose mothers had completed tertiary school or university. These results evidence an urgent need to implement

TABLE 2. Percent distribution of unfavorable health status among students in Bariloche in relation to sociodemographic and family characteristics $(n=180)$. Comparison using a Chi-square test

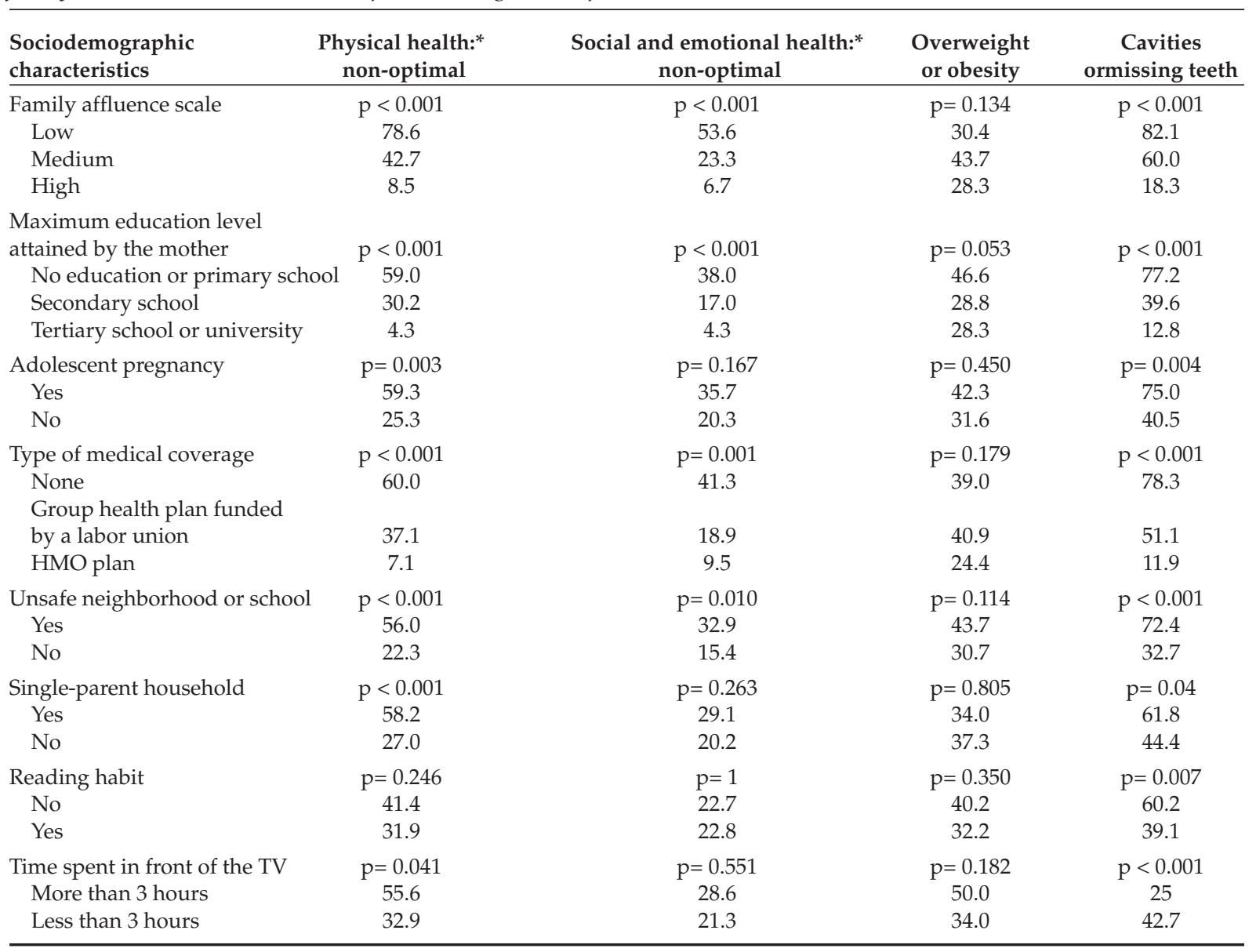

* Parental perception of nutritional status. 
oral health promotion and prevention programs. This disease is as common as it is preventable through daily teeth brushing and controlled candy consumption. ${ }^{30}$

Overweight and obesity prevalences were high: $27.3 \%$ and $8.7 \%$, respectively. However, such prevalences are similar to those observed in other assessments on child nutrition conducted in different Argentine regions, where percentages ranged from $10.9 \%$ to $25.6 \%$ for overweight, and from $3.8 \%$ to $13.8 \%$ for obesity. $7,8,31$

Although no comparative studies have been conducted, this problem tends to be worse in the Patagonian region. ${ }^{8}$

Like other studies conducted in Argentina, no relationship between nutritional status and studied sociodemographic characteristics was observed..$^{6,8,10}$ This may be related to the consumption of high-calorie foods and the lack of physical activity. Considering its high prevalence, obesity should become a priority for public health.

Overweight children tend to become obese adults; therefore, preventing child obesity entails preventing adult obesity. Adult obesity is a risk factor for chronic diseases, for example, hypertension, heart problems and diabetes, which are major determinants for early morbidity and mortality during adulthood. School programs that promote changes in children and family eating habits are essential to establish long-lasting healthy eating patterns and lifestyles. ${ }^{32,33}$

The type of health insurance shows a significant association with social and emotional health: $40 \%$ of children with no medical coverage have a non-optimal social and emotional health.

FIGURE 1. Percentage of school-aged children in Bariloche with an unfavorable health outcome in relation to the number of risk factors

Physical health: non-optimal

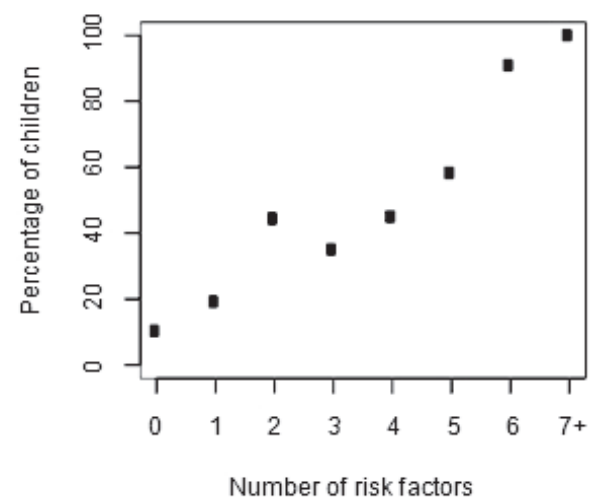

Overweight or obesity

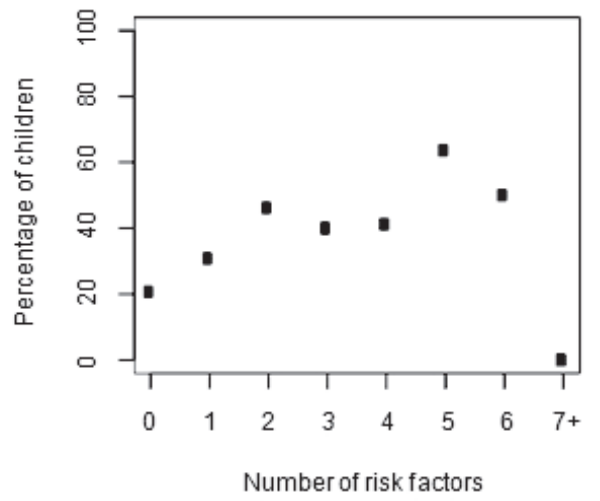

Social and emotional health: non-optimal

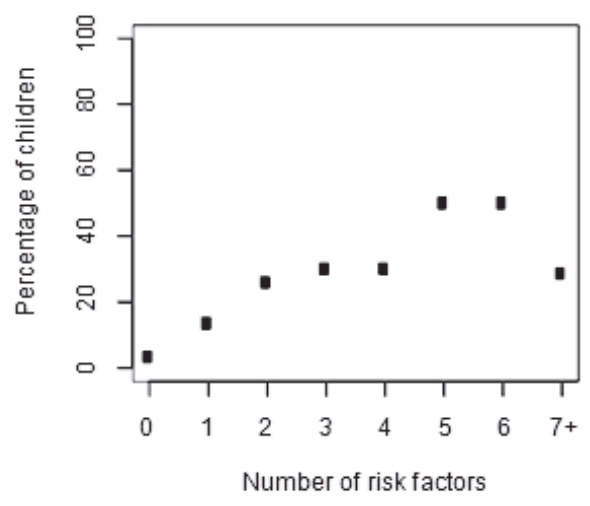

Cavities or missing teeth

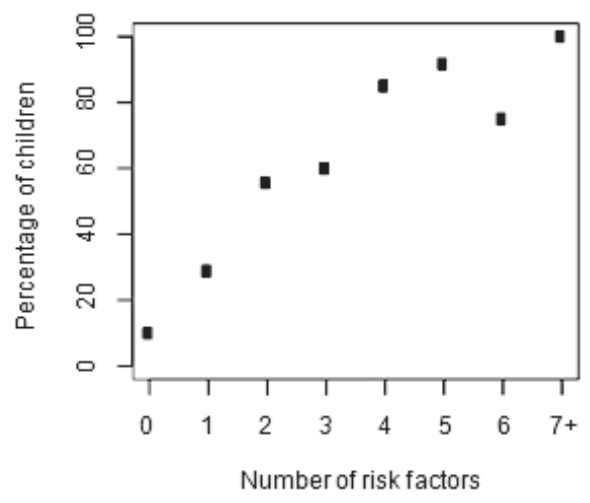


At present, the Bariloche regional hospital offers no pediatric psychology services. This suggests that children who need such care have problems receiving it.

The scope of this study is restricted due to sample representativity limitations. In addition, only one pediatrician administered the surveys at the 2 de Abril Health Center and, even though the interview had been carefully planned among healthcare providers, this may be indicative of a source of research bias. However, this study makes an important contribution to knowledge regarding local health inequalities, which have not been addressed in previous studies. These results reveal the need to pay attention to child health in the city of Bariloche, especially oral health, in order to avoid further deterioration of disadvantaged sectors.

We found that each sociodemographic characteristic is independently associated with some of the studied health outcomes. In addition, we detected that the possibility of having unfavorable health outcomes increases gradually with the number of risk factors. These results are consistent with those observed in other studies on the importance of the total number of risk factors on child health. ${ }^{18,34}$ In this regard, social and health programs that address the concurrence of multiple factors are expected to strongly influence child health.

Health problems have an impact on children's academic performance and are also associated with a higher possibility of adolescent pregnancy, criminal activities, unemployment, and adult depression. ${ }^{35}$ Epidemiological knowledge gained will allow to guide program planning in the field of health and social welfare aimed at reducing health inequalities in Bariloche and other similar locations. Besides, such knowledge will be the basis for developing research projects in relation to child health inequalities.

\section{CONCLUSIONS}

Major gaps in child health were observed in the studied sample of students in Bariloche.

Multiple risk factors have a cumulative effect on general, social and emotional, and oral health. The possibility of having a non-optimal health status increases 1.8 times with each risk factor. The risk of social and emotional problems is 1.4 times higher with each risk factor, while the possibility of having cavities or missing teeth is twice as high.

Overweight and obesity prevalences reached worrying proportions: $27.3 \%$ and $8.7 \%$, respectively.

\section{REFERENCES}

1. Pan American Health Organization. Health statistics from the Americas, 1998. Washington DC; 1999.

2. Alleyne GA, Castillo-Salgado C, Schneider MC, Loyola E, et al. Overview of social inequalities in health in the region of the Americas, using various methodological approaches. Rev Panam Salud Publica 2002;12(6):388-97.

3. Lejarraga H, Pascucci M, Krupitzky S, Kelmansky D, et al. Psychomotor development in Argentinean children aged 0-5 years. Paediatr Perinat Epidemiol 2002;16(1):47-60.

4. Garibotti G, Comar H, Vasconi C, Giannini G, et al. Desarrollo psicomotor infantil y su relación con las características sociodemográficas y de estimulación familiar en niños de la ciudad de Bariloche, Argentina. Arch Argent Pediatr 2013;111(5):384-90.

5. Torralva T, Cugnasco I, Manso M,Sauton F, et al. Desarrollo mental y motor en los primeros años de vida: su relación con la estimulación ambiental y el nivel socio-económico. Arch Argent Pediatr 1999;97(5):306-16.

6. Chesta M, Lobo B, Agrelo F, Carmuenga E, et al. Evaluación antropométrica en niños de la ciudad de Córdoba, año 2000. Arch Argent Pediatr 2007;105(2):101-8.

7. Bejarano I, Dipierri J, Alfaro E, Quispe Y, et al. Evolución de la prevalencia de sobrepeso, obesidad y desnutrición en escolares de San Salvador de Jujuy. Arch Argent Pediatr 2005;103(2):101-9.

8. Kovalskys I, Bay L, Rausch Herscovici C, Berner E. Prevalencia de obesidad en una población de 10 a 19 años en la consulta pediátrica. Arch Argent Pediatr 2003;101(6):441-7.

9. Juiz de Trogliero C, Morasso MC. Obesidad y nivel socioeconómico en escolares y adolescentes de la ciudad de Salta. Arch Argent Pediatr 2002;100(5):360-6.

10. Poletti $\mathrm{OH}$, Barrios L. Obesidad e hipertensión arterial en escolares de la ciudad de Corrientes, Argentina. Arch Argent Pediatr 2007;105(4):293-8.

11. Llompart G, Marin GH, Silberman M, Merlo I, et al. Oral health in 6-year-old schoolchildren from Berisso, Argentina: falling far short of WHO goals. Med Oral Patol Cir Bucal 2010;15(1):e101-5.

12. Yankilevich ER, Cattoni ST, Cornejo LS, Battellino LJ. Distribución de la caries dental en niños preescolares en una región urbana, Argentina, 1992. Rev Saude Publica 1993;27(6):436-44.

13. Buchbinder M. Mortalidad infantil y desigualdad socioeconómica en la Argentina. Tendencia temporal. Arch Argent Pediatr 2008;106(3):212-8.

14. De Sarasqueta P. Mortalidad neonatal y posneonatal en recién nacidos de peso menor a $2500 \mathrm{~g}$ en la República Argentina (1990-1997). Arch Argent Pediatr 2001;99(1):59-61.

15. Sociedad Argentina de Pediatría. Guía para el pediatra. Invitemos a leer: Programa de promoción de la lectura. Buenos Aires; 2002.

16. National Research Council. Children's health, the Nation's wealth: assessing and improving child health. Washington, DC: National Academies Press; 2004.

17. Blumberg SJ, Olson L, Frankel MR, Osborn L, et al. Design and operation of the National Survey of Children's Health, 2003. Vital Health Stat 1 2005;(43):1-131.

18. Larson K, Russ SA, Crall JJ, Halfon N. Influence of multiple social risks on children's health. Pediatrics 2008;121(2):337-44.

19. Brothers KB, Glascoe FP, Robertshaw NS. PEDS: developmental milestones- an accurate brief tool 
for surveillance and screening. Clin Pediatr (Phila) 2008;47(3):271-9.

20. Glascoe FP. Parents' evaluation of developmental status: how well do parents' concerns identify children with behavioral and emotional problems?. Clin Pediatr (Phila) 2003;42(2):133-8.

21. Cole TJ, Bellizzi MC, Flegal KM, Dietz WH. Establishing a standard definition for child overweight and obesity worldwide: international survey. BMJ 2000;320(7244):1240-3.

22. Cole TJ, Flegal KM, Nicholls D, Jackson AA. Body mass index cut offs to define thinness in children and adolescents: international survey. BMJ 2007;335(7612):194.

23. Currie C,Molcho M, Boyce W, Holstein B, et al. Researching health inequalities in adolescents: The development of the Health Behaviour in School-Aged Children (HBSC) family affluence scale. Soc Sci Med 2008;66(6):1429-36.

24. RDevelopmentCore Team. R: a language and environment for statistical computig. Vienna: R Foundation for Statistical Computing; 2013.

25. Organización Mundial de la Salud. Determinantes sociales de la Salud. [Accessed on: April 14, 2015]. Available at: http://www.who.int/social_determinants/final_report/ key_concepts/es/

26. Braveman P. Health disparities and health equity: concepts and measurements. Annu Rev Public Health 2006;27:167-94.

27. Lurie N, Dubowitz T. Health disparities and access to health. JAMA 2007;297(10):1118-21.

28. Argentina. Ministry of Health of Argentina. School Health
Program. [Accessed on: April 14,2015]. Availableat: http:/ / www.msal.gov.ar/index.php/programas-y- planes /229programa-de-sanidad-escolar.

29. Ravera E, Sanchez GA, Squassi AF, Bordoni N. Relationship between dental status and family, school and socioeconomic level. Acta Odontol Latinoam 2012;25(1):140-9.

30. Walker KK, Steinfort EL, Keyler MJ. Cues to action as motivators for children's brushing. Health Commun 2014:1-11.

31. Padilla IS. Prevalencia de sobrepeso-obesidad y factores asociados con valor predictivo-preventivo en escolares de a 11 años de Río Gallegos, Santa Cruz, Argentina. Salud Colect 2011;7(3):377-88.

32. Flynn MA, McNeil DA, Maloff B, Mutasingwa D, et al. Reducing obesity and related chronic disease risk in children and youth: a synthesis of evidence with "best practice" recommendations. Obes Rev 2006;7(Suppl1):7-66.

33. Avery A, Bostock L, McCullough F. A systematic review investigating interventions that can help reduce consumption of sugar-sweetened beverages in children leading to changes in body fatness. J Hum Nutr Diet 2015;28(Suppl 1):52-64.

34. Sameroff AJ. Environmental risk factors in infancy. Pediatrics 1998;102(5 Suppl E):1287-92.

35. Haskins R, Rouse C. Closing achievement gaps. Future Child. 2005. [Accessed on: April 14, 2015]. Available at: http://futureofchildren.org/futureofchildren / publications/docs/15_01_PolicyBrief.pdf. 


\section{Annex 1 \\ Child psychophysical health status in relation to the socioeconomic status: interdisciplinary exchange, Centro Regional Universitario Bariloche - Bariloche Health Centers}

Date: Survey taker:

Site:

Reason for consultation: Follow-up Medical certificate

Others (specify):

Date of previous consultation (as per medical record):

Identifying information

1. Age: ......... years old

2. Date of birth: Does not know

3. Birth weight:

Less than $2.5 \mathrm{~kg}$

More than $2.5 \mathrm{~kg} \square$

Does not know

4. Preterm infant? Yes $\square$ No

5. Gender: Female Does not know

6. Attending school: Public $\square \quad$ Private
Does not know

7. School grade:

ot attending school

Does not know

8. Number of siblings (from the same mother)?

9. Person accompanying the child:
Mother
Father
Others (specify):

10. Mother's age: years old

Deceased

Does not know

11. Mother's age when she had her first child:

Younger than 15 years old

16 to 18 years old

26 to 35 years old

Older than 35 years old

19 to 25 years old

Does not know

12. Maternal education (check the highest completed level):

No education

University
Primary school

Does not know
Secondary school

Others:

13. Paternal education (check the highest coleted level):
No education
Primary school
Secondary school
Tertiary school
University
Does not know
Others:

14. Does the child live at home with his/her mother and father?
Yes
No
Does not know

15. Any family member is of Mapuche descent?
Yes
No
Does not know 


\section{Physical and oral health}

1. Weight $\mathrm{kg}$

Date measured:

2. Height: $\mathrm{cm}$

Date measured:

3. Cavities:

Yes $\square$

No $\square$

Does not know

4. Missing teeth:
Yes $\square$
No
Does not know

5. Complete vaccinations as per the National Immunization Schedule:
Yes
No
Does not know

6. Varicella vaccine:

Yes

No

Does not know

7. Hepatitis A vaccine:

Yes

No $\square$

Does not know

8. Overall, how would you describe the child's health?
Excellent
Very good
Fair
Poor
Does not know

9. How would you describe the child's dental condition?
Excellent
Very good
Fair
Poor
Does not know

10. Child's eating habits:
Excellent
Very good
Fair
Poor
Does not know

11. How long was the child breastfed?
Never
Less than 1 month
1 to 3 months
3 to 9 months
More than 9 months
Does not know

12. During the past week, how many days did the child do physical exercise for more than 20 minutes that made him/her sweat or breathe hard?
0 days
1-3 days
4-6 days
Everyday
Does not know

13. During the past year, about how many days did the child miss school because of illness or injury?
0 days
1-5 days
6-10 days
More than 11 days
Does not know

14. During the past 12 months, did the child get hurt and required medical care?
Yes
No
Does not know

15. During the past 12 months, has the child been admitted to the hospital?
Yes
No
Does not know

16. Reasons for hospitalization during the past 12 months (check all that apply):

Respiratory disease

Trauma or injury

Surgical pathology

Dental infection

17. During the last 12 months, has the child suffered any burn?

Yes

No

Does not know 


\section{Emotional and mental health}

1. Please indicate whether you are concerned or not in relation to the following.

Concerned

Not concerned

How the child behaves

How the child does in school

How the child relates with other children

How other students treat the child

How teachers and other adults treat the child

The child's relationship with his/her mother

The child's relationship with his/her father

How the child understands instructions given to him/her

Depression or anxiety in the child

Violence in the house, school or neighborhood

Drug abuse

Alcohol abuse

Eating disorders in the child

How the child solves conflictive situations

The child's manner of speech

\section{Health insurance}

1. What kind of medical coverage does the child have?

HMO plan $\square$ Group health plan funded by a labor union $\square \quad$ None $\square \quad$ Does not know

2. During the past 12 months, did the child lack medical coverage for any given period?
Yes
No
Does not know

3. Does the child's medical coverage include visits to the dentist and dental work?
Yes
No
Does not know

4. In general, when you make a not urgent appointment to see the child's doctor, it takes place:

On the same or next day

6 to 15 days later

3 to 5 days later

More than 15 days later

\section{Preventive medicine and alternative medicine}

1. During the past 12 months, have you taken the child to the doctor for a checkup?
Yes $\square$
No
Does not know

2. During the past 12 months, have you taken the child to the dentist for a checkup?
Yes
No $\square$
Does not know

3. During the past 12 months, have you taken the child to the dentist for dental work?
Yes $\square$
No $\square$
Does not know

4. During the past 12 months, how many times did you take the child to see a doctor without an appointment?
0
1
2 or more
Does not know

5. Does the child have a doctor who knows him/her well and is aware of his/her medical history?
Yes
No $\square$
Does not know

6. During the past 12 months, have you attended an alternative medicine practice for your child, his/ her siblings or you or your partner?

No

Homeopath

Healer

Others (specify): 
7. Do you use medicinal herbs to treat the child?
Yes
No
Does not know

\section{School and recreational activities}

1. During the past 12 months, did the child participate in relatively organized sports activities or take lessons beyond what is required at school?
Yes
No $\square$
Does not know

2. During the past 12 months, did the child participate in any other activity or organized event?
Yes
No $\square$
Does not know

3. On a school day, about how much time does the child read or has another person read to him/her for pleasure beyond school requirements?
0
30 to 60 minutes
Less than 15 minutes
More than 1 hour
15 to 30 minutes
Does not know

\section{Health and family activities}

1. In general, how would you describe the mother's health?
Excellent
Very good
Good
Fair
Poor $\square \quad$ Does not know

2. Does the mother talk to her children?
Every day
Sometimes
Never $\square$
Does not know

3. Does the mother set limits to her children?
Always
Sometimes
Never
Does not know

4. Does any household member smoke?
Yes
No
Does not know

5. Does any household member have problems with alcohol?
Yes
No $\square$
Does not know

6. On a work day, about how much time does the mother spend with her child?
Less than 2 hours
More than 8 hours
2 to 4 hours
Does not know
4 to 8 hours

7. Does any household member have a car?
Yes
No $\square$
Does not know

8. How many people share the bedroom with the child?
None
1
2
3 or more
Does not know

9. During the past 12 months, how many times was the child on vacations outside Bariloche for more than 3 days?
None
1
2
3 or more
Does not know

10. How many computers are there in the house?
None
1
2 or more
Does not know

11. the past 12 months, has any household member received any type of benefit or food allocation? (E.g., unemployment benefit, Habitar en Familia [a housing allowance], Comer en familia (a meal allowance), PESA [Social Emergency Food Program]).
Yes
No
Does not know

12. During the past week, have you or has a family member taken the child out (park, friends' or family member's house, hill, lake, restaurant, etc.)?
No
1-3 times
4-6 times
7 or more times
Does not know 
13. Last week how many days did the child read on his/her own or you or other family member read to the child a short story or part of a novel?
None
1-3 days
4-6 days
Every day
Does not know

14. In the past week, how many days did all family members eat a meal together?

None $\square \quad$ 1-3 days $\square \quad$ 4-6 days $\square \quad$ Every day $\square \quad$ Does not know

15. The last day the child attended school, did he/she eat breakfast before going to school?
Yes
No $\square$
Does not know

16. On a school day, how many hours does the child spend watching TV, videos, or playing computer games?

None $\square \quad$ Less than 1 hour $\square \quad 1-3$ hours $\square \quad 4$ or more hours

17. In the past week, was the child alone in the house, even for a short period?
Yes
No $\square$
Does not know

18. How many hours does the mother work outside the house?
None
Less than 4 hours
4-8 hours
8 or more hours
Does not know

19. During the past 12 months, has anyone in the family been asked to leave his/her job or make an important job change in order to look after the child?
Yes
No $\square$
Does not know

20. How often do you feel the child is safe in your neighborhood?
Never
Sometimes
Usually

Always

Does not know

21. How often do you feel the child is safe in school?
Never
Sometimes
Usually
Always
Does not know 